\title{
Comment on: Holt HB, Wild SH, Postle AD et al (2007) Cortisol clearance and associations with insulin sensitivity, body fat and fatty liver in middle-aged men. Diabetologia 50:1024-1032
}

\author{
M. N. Kerstens • R. P. F. Dullaart
}

Received: 24 May 2007 / Accepted: 25 May 2007 / Published online: 22 June 2007

(C) Springer-Verlag 2007

Keywords Cortisol metabolism · Insulin resistance ·

Salt sensitivity

To the Editor: In their interesting study, Holt et al. [1] studied the metabolism of cortisol and its relationship with insulin sensitivity in a group of middle-aged healthy men, with adjustment for fat content, fat distribution and for the presence of non-alcoholic fatty liver disease. One of their key observations was the demonstration of a significant inverse correlation between cortisol clearance and insulin sensitivity, but several methodological issues may hamper the interpretation of their results.

First, Holt et al. were not able to demonstrate any correlation between cortisol clearance and plasma cortisol (measured at 09:00 hours and following $\mathrm{ACTH}_{1-24}$ stimulation) or urinary-free cortisol excretion, which constitutes less than $1 \%$ of the total urinary excretion of cortisol and its metabolites [2]. Only cortisol clearance is documented in this paper, and no data are provided concerning cortisol production, which can probably be assessed using kinetic methods and by measurement of urinary cortisol metabolite excretion [3, 4]. Both parameters of cortisol metabolism and measurements of integrated circulating cortisol levels are required for evaluation of the inter-relationship between cortisol metabolism and insulin sensitivity.

M. N. Kerstens $(\square) \cdot$ R. P. F. Dullaart

Department of Endocrinology,

University Medical Center Groningen,

9700 RB Groningen, the Netherlands

e-mail: m.n.kerstens@int.umcg.nl
Second, sodium intake was not controlled for in their study subjects. We have demonstrated that the effects of salt loading on urinary cortisol metabolites vary between individuals, some of whom show a rise in blood pressure after salt loading (i.e. salt-sensitive subjects), while others do not (i.e. saltresistant subjects) [5]. In healthy salt-resistant subjects, it was found that cortisol metabolite excretion was increased after a high-salt diet, whereas it was decreased in healthy saltsensitive subjects. These changes in cortisol metabolite excretion were inversely correlated with changes in plasma cortisol, which suggests that higher cortisol elimination may result in lower circulating cortisol. In the same study, it was also observed that changes in insulin sensitivity (according to the homeostasis model assessment of insulin resistance [HOMA-IR]) were positively correlated with changes in plasma cortisol and negatively correlated with changes in cortisol metabolite excretion. In other words, a sodiuminduced increase in cortisol metabolite excretion may result in a decrease in plasma cortisol and an increase in insulin sensitivity. Clearly, our results are at variance with those by Holt et al. with respect to cortisol metabolism and insulin sensitivity. Moreover, other factors may also modify these sodium balance-related variations in insulin sensitivity, as it was recently demonstrated that a high dietary sodium intake increases adiponectin levels, probably secondary to a sodiuminduced decrease in angiotensin II [6]. Thus, it is important to control sodium intake when studying the relationship between cortisol metabolism and insulin sensitivity.

Given the complex relationship between cortisol metabolism and insulin sensitivity, future studies should preferably include extended measurements of cortisol kinetics. Furthermore, these investigations should account for mod- 
ulating factors of the cortisol effect at the tissue level, such as $11 \beta$-hydroxysteroid dehydrogenase activity and polymorphisms in the glucocorticoid receptor gene $[7,8]$.

Duality of interest The authors declare that there is no duality of interest associated with this manuscript.

\section{References}

1. Holt HB, Wild SH, Postle AD et al (2007) Cortisol clearance and associations with insulin sensitivity, body fat and fatty liver in middle-aged men. Diabetologia 50:1024-1032

2. Shackleton CH (1993) Mass spectrometry in the diagnosis of steroid-related disorders and in hypertension research. J Steroid Biochem Mol Biol 45:127-140
3. Kraan GP, Dullaart RPF, Pratt JJ et al (1998) The daily cortisol production reinvestigated in healthy men. The serum and urinary cortisol production rates are not significantly different. J Clin Endocrinol Metab 83:1247-1252

4. Zumoff B, Fukushima DK, Hellman L (1974) Intercomparison of four methods for measuring cortisol production. J Clin Endocrinol Metab 38:169-175

5. Kerstens MN, van der Kleij FG, Boonstra AH et al (2003) Salt loading affects cortisol metabolism in normotensive subjects: relationships with salt sensitivity. J Clin Endocrinol Metab 88: $4180-4185$

6. Lely AT, Krikken JA, Bakker SJ, et al (2007) Low dietary sodium and exogenous angiotensin II infusion decrease plasma adiponectin concentrations in healthy men. J Clin Endocrinol Metab 92: 1821-1826

7. Stewart PM, Krozowski ZS (1999) $11 \beta$-hydroxysteroid dehydrogenase. Vitam Horm 57:249-324

8. van Rossum EF, Lamberts SW (2004) Polymorphisms in the glucocorticoid receptor gene and their associations with metabolic parameters and body composition. Recent Prog Horm Res 59:333-357 